\title{
Medicine and Smart Phones
}

\section{Kayastha R}

Kathmandu University School of Medical Sciences

Dhulikhel, Nepal.

A friend of mine, a MBBS doctor, recently was visited by a late teenager with knee pain for a checkup and could not come to a single diagnosis was taken aback when his patient suggested Osgood Schllater's disease, especially when he had a little idea of the disease process itself. A practicing doctor, even in Nepal, faces the patients, who have their diagnosis along with their treatment in their hands, just visiting "to be sure." Thanks from the digital world.

The world seems to be going at a frantic pace. Medicine could not have remained an outcast. The growth of knowledge and ever changing practice makes it utterly impossible to catch up to, if we were to stay on the other side of technology. The vast number of pages that demands bigger bookshelves and strong back are now slowly taking a backstage as the electronic version of them just slips into the pocket, just a finger touch away. Topol EJ, in his book "The Creative Destruction of Medicine: How the Digital Revolution Will Create Better Health Care", says a consumer revolution will fundamentally change the way medicine is practiced. ${ }^{1}$

Smart phones with the internet connections save a hassle at many times, questions during the rounds for students, a quick recall just before a viva-voce, a knowledgeable patient, new therapy, and new issue of a journal. It saves the long walk to library and searching through the index just to find out that you have the wrong volume in the hand. Doctors and students have an obligation to provide a good standard of practice and care and keep their professional knowledge and skills up to date. Mobile medical apps will play a pivotal role in this process, but will apps provide the user with up to date evidence and the highest clinical standards for healthcare?

Smart phones with all the variety of medical apps make your life much simpler if you have hands on the right ones. The selection of the application however can prove to be a headache, especially when the quacks are prevalent in higher quantity than the real ones. Apple has more than 10000 apps in the medical section and Android features more than 3300 medical apps. ${ }^{2}$ It is uncertain if these apps are reliable, evidence based, and developed without conflicts of interest.

So question of how to choose a proper app that is reliable and up to date remains a question. Due to lack of proper regulation in the apps being developed it lies in the hand of a user to accept or refuse the apps based on his judgment. The series of questions such as if the article is published by medical publisher, referencing, authors, peer reviewed, feedback, primary audience of the article (doctors / patients), any particular interest to the app provider (drug company?), patient privacy and conflict of interest can be of much help in decision making. ${ }^{3}$

The problem also arises when the patient comes with wrong information about his disease and has a delusional belief in it rather than the doctors. A thoughtful and convincing act of a doctor is much needed, rather than frustration that can easily cross the mind in these situations.

Healthcare and health education are reaching a critical convergence with technology that will revolutionize how patients are treated, how doctors provide care, how drugs are developed, and how people maintain their health. And for my friends using phones and caught during the rounds always will have excuses of "just reviewing the case", thanks for SMS and book in the same device.

The easy access to the answers for the students during the exams, as they can always SMS the question or look into the book for the matter or even the bluetooth the answer can be serious threat to the current settings of examination. The digital world can evoke a person to learn less and depend much on his apps and e-books. This matter needs to be seriously looked upon by the authority concerned.

\section{REFERENCES}

1. Topol EJ. The Creative Destruction of Medicine: How the Digital Revolution Will Create Better Health Care. New York: Basic Books; 2012.

2. App Store Metrics. Appliction category distribution. 2012. Available from http://148apps.biz/app-store-metrics/?mpage=catcount.

3. Visser BJ, Bouman J. There's a medical app for that. [Internet]. BMJ careers; 2012 Apr. Available from http://careers.bmj.com/ careers/advice/view-article.html?id=20007104. 